\title{
Generic Aggregated Wind Farm Model for Power System Simulations - Impact of Grid Connection Requirements
}

\author{
J. Soens, J. Driesen, D. Van Hertem, R. Belmans \\ Department of Electrical Engineering \\ ESAT/ELECTA, K.U.Leuven \\ Kasteelpark Arenberg 10, B-3001 Leuven (Belgium) \\ phone: +32 16 321031, fax: +3216321985 \\ e-mail: joris.soens@esat.kuleuven.ac.be
}

\begin{abstract}
A generic dynamic model of a large wind farm is used to simulate the grid impact of an offshore wind farm in Belgium. The voltage fluctuations during wind speed changes and grid disturbances are simulated. The outcome depends on the performance of the dynamic voltage support that the wind farm can deliver.
\end{abstract}

\section{Keywords}

Power system simulation, Wind power generation, Wind power modelling

\section{Introduction}

The steadily increasing amount of wind power throughout various UCTE-countries puts new challenges to the power system operators, who have to ensure a reliable, safe and economically manageable grid operation. Therefore, the modelling of wind turbines for power system simulations is a matter of high interest. The development of these models has been the subject of many discussions: it requires a compromise between making substantial simplifications to reduce computational efforts on the one hand, and maintaining the necessary adequacy to be able to predict the farm's influence on the system's dynamic behaviour on the other hand.

With adequate dynamic models, more insight is obtained about the ability of a wind farm to provide 'grid support'. 'Grid support', also known as 'ancillary services', represents a number of services that the power system operator requires from power generators, in order to secure a safe, reliable, stable and economically manageable grid operation. These 'ancillary services' include support for:

- (fast) output power or frequency control;

- voltage control;

- black start capability;

- economic dispatch and financial trade reinforcements

The relation between wind farms and grid support has been extensively discussed over the past years, especially in Denmark and Germany, where the relative amount of wind power in the power grid is the highest of Europe. Specific grid connection requirements for wind turbines were issued first by the Danish and German grid operators, and are used as a reference by most European grid operators who have to take a large amount of wind power in their power system into account. An overview of existing grid connection requirements is given in [2] (specific for wind turbines) and [3] (dispersed generation in general).

The actual existing grid connection requirements are mainly focussed on the first two mentioned ancillary services: (fast) output power control and voltage control. For these issues, the advanced wind turbine generators can be considered as competent as conventional generators.

On the other hand, even the most advanced turbine technology does hardly improve the capability of wind power to facilitate the economic dispatch of the power market and financial trade reinforcements. These issues can not be enforced by technical grid connection requirements, but must be part of the economical risk that a wind farm operator is willing to take. The criterion for success in these issues is mainly the accuracy of wind speed predictions on a (mid-)long term, rather than the turbine technology. This will not be further discussed in this paper.

In this paper, the importance of a wind farm's capability to provide voltage control is examined. As an example study case, simulations are performed for a hypothetical offshore wind-farm in the Belgian North-Sea. A simplified generic model is used for the wind farm. This model is fully described in [4] and is only shortly reviewed in the next section. The used power system simulation software is EUROSTAG.

This work is part of the multidisciplinary research project 'Optimal Offshore Wind Development in Belgium', funded by the Belgian Federal Science Office. The project takes meteorological, geological, technological and economical aspects of offshore wind power in Belgium into account, as well as the grid availability. The 
static load-flow results for the grid availability have already been published in [5]. It was concluded there that an installed offshore wind power of more than $500 \mathrm{MW}$ in Belgium will require major grid reinforcements both in the coast region and further inland, which is not expected to happen in the near future, considering the difficulties in obtaining permits for constructing new power lines.

\section{Wind Farm Model}

\section{A. Generic Active Power Model}

A full description of the generic wind farm model can be found in [4]. The active power model starts from a detailed model of a variable speed turbine, published by the manufacturer [6]. This model was used to perform simulations with sinusoidal wind speeds with a varying average value and varying fluctuation frequency (Fig. 1). All simulation results are summarized in the plot of Fig. 2, in which the amplitude of the power oscillations is plotted against the fluctuation frequency of the wind speed, using the average wind speed as parameter.

Two sets of curves can be distinguished: curves for high average wind speed (slope $20 \mathrm{~dB} /$ decade in low frequency region) and for low average wind speed (horizontal in low frequency region). The reason for this is the different effect of speed and pitch control of the turbine, below and above rated wind speed.
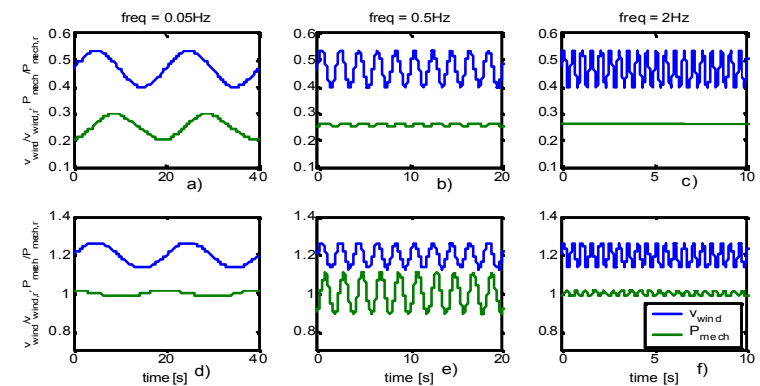

Fig. 1. Wind speed and mechanical power for two values of average wind speed and three different wind speed fluctuation frequencies

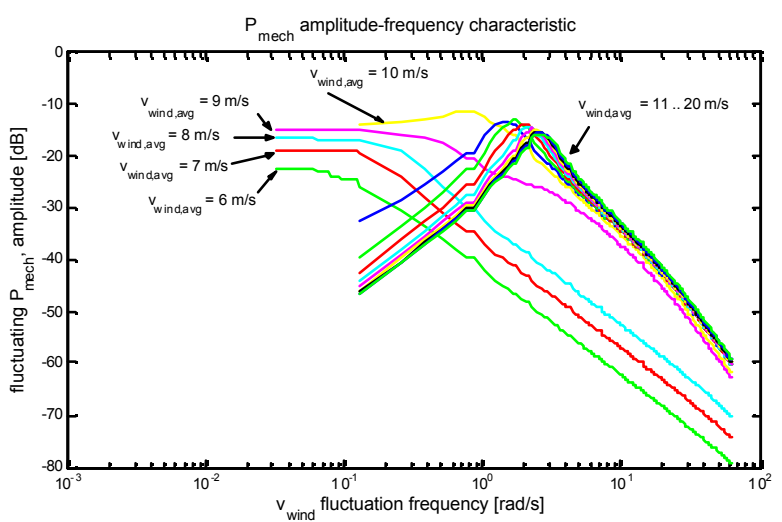

Fig. 2. Frequency Characteristic of Power Fluctuation Amplitude
The curves of Fig. 2 suggest to simplify the detailed active power model by two equivalent transfer functions, one for high and one for low wind speeds (Fig. 3). The time constants are calculated to have an optimal match between the curves of and the frequency response of the transfer functions. Suggested values are:

$$
\begin{array}{llll}
T_{\text {low }} & =7 \mathrm{~s} & d & =0.3 \\
T_{0} & =0.5 \mathrm{~s} & K_{\text {high }} & =0.06
\end{array}
$$

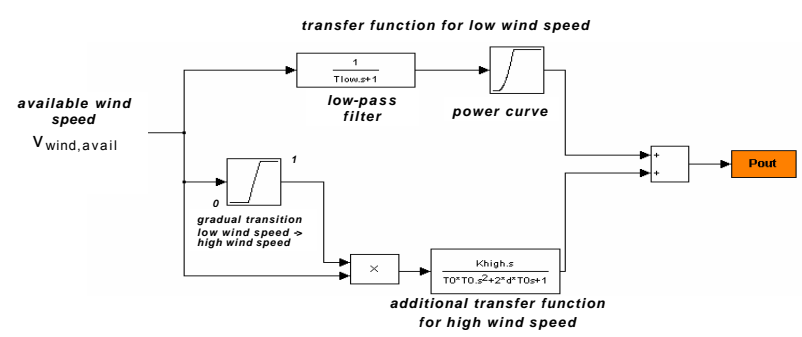

Fig. 3. Equivalent Transfer Function for Active Power

Thus, an equivalent active power model for a wind turbine is constructed, which is well suitable to estimate the turbine power fluctuations during continuous operation. The full explanation of the model derivation, as well as the aggregation into a model of an entire wind farm, is given in [4]. Also the simplified simulation of turbine yawing and active power control is given in [4].

\section{B. Generic Reactive Power Model}

The modelling of the reactive power generation and the behaviour during grid disturbances does not start from a predefined detailed model from literature. It is believed that future large wind farms will always be able to control the reactive power output, either by control action on the generator itself or by additional devices (such as SVCs or STATCOMs) connected at the point of common coupling.

The supplied reactive power is calculated by either a $\mathrm{P}$ controller or PI-controller with anti-windup, to avoid that the reference reactive power exceeds a limit value. The implementation of a PI-controller is supported by most power system simulation software packages, and does not contain any particularities in its use for this model.

The speed of the reactive current control depends on the generator type. The two most common generator types for variable speed turbines are

- doubly fed induction generators

- synchronous generators with frequency converter, (mostly combined with a 'direct drive' turbine configuration)

The current control loop for the reactive power is modelled as a first order delay (from reference current towards produced current). The current control loop of the synchronous generator is much faster than with the doubly fed induction generator, as the full active and reactive power is processed by power electronic converters. Suggested values for the time constant TICTL (the time constant of the current control loop) are:

- $T I C T L=2 \mathrm{~s}$ for poorly advanced technology 
- $T I C T L=200 \mathrm{~ms}$ for advanced technology (doubly fed induction generator)

- TICTL = $20 \mathrm{~ms}$ for highly advanced technology (synchronous generator with PWM-converter, or a STATCOM connected parallel with the farm)

A detailed description about the modelling of the current controller, as well as the impact of the reactive current control on the active power control (in case of overcurrents) can be found in [4]. It is assumed that the reactive power has priority on the active power, i.e. in case of reactive power demand and high machine currents, the active power must be decreased in order to supply the reactive power, without exceeding the rated currents.

\section{Simulations}

\section{A. Assumptions for Simulated Scenarios}

\section{Wind Farm}

The wind farm is assumed to consist of five turbine rows behind each other, orthogonal to the wind speed direction. The wind farm installed power is $500 \mathrm{MW}$.

\section{Grid Connection}

The grid connection is shown in Fig. 4. The wind farm power is assumed to be collected at $30 \mathrm{kV}$, and transformed by an offshore transformer towards $150 \mathrm{kV}$. The grid connection is made by a submarine $150 \mathrm{kV}$ cable. There are three $150 \mathrm{kV}$-substations available at the Belgian coast (Slijkens, Zeebrugge and Koksijde). The wind farm is assumed to be connected at Slijkens.

The cable characteristics have impact on the simulation results, especially its capacitance is not neglectible, As the cable consumes a lot of capacitive power, two inductors are assumed, each of them compensating half of the cable capacitive power in no-load condition. One is installed at Slijkens, the other at the $150 \mathrm{kV}$ offshore substation. The inductors are not controlled and do not have an impact on the dynamic simulations.

\section{Belgian Power System Model}

An Eurostag model of the Belgian power grid was used, containing:

- all $400 \mathrm{kV}, 220 \mathrm{kV} 150 \mathrm{kV}$ and $70 \mathrm{kV}$ substations and high voltage lines of Belgium, including the planned $150 \mathrm{kV}$ cable between the coastal nodes Koksijde and Slijkens;

- all generation and load data for each substation, as they have been recorded on a representative winter day (19/01/1994);

- dynamic models of the governors and voltage controllers of most generators in the Belgian power system, including the power plant of Herdersbrug (2x 144MW and 1 x $165 \mathrm{MW})$, which is the nearest power plant to the coast.

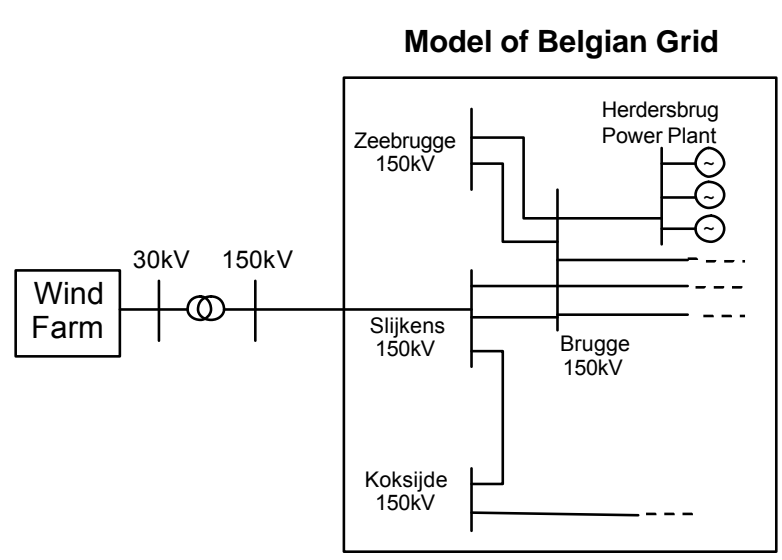

Fig. 4. Connection of Wind Farm to Belgian Grid

\section{B. Wind Speed Changes}

The impact of wind speed changes on the voltage on the grid node at which the farm is connected is investigated. Four scenarios are considered:

a) the wind farm is controlled to produce nor consume reactive power at the offshore $150 \mathrm{kV}$-node; the transmission cable length is $10 \mathrm{~km}$

b) same as $a$ ), but with a cable length of $50 \mathrm{~km}$;

c) the wind farm reactive power is dynamically controlled in such a way that the voltage at Slijkens remains at a fixed value (i.e. the initial voltage without wind power production). The transmission cable length is $10 \mathrm{~km}$;

d) same as $c$ ), but with a cable length of $50 \mathrm{~km}$.

A wind speed sequence as in Fig. 5 is assumed. Starting from $10 \mathrm{~m} / \mathrm{s}$, the wind speed rises at $14 \mathrm{~m} / \mathrm{s}$ (i.e. the turbine rated wind speed), and then further to $25 \mathrm{~m} / \mathrm{s}$ (i.e. just below the cut-out wind speed). The wind speed direction undergoes a sudden change of 28 degrees $(0.5$ radians) at $\mathrm{t}=5000 \mathrm{~s}$. The turbines must yaw towards the new wind direction. The mismatch angle between the wind direction and the turbines orientation, calculated according to the model description in [4] is also shown in Fig. 5.

The active power production is shown in Fig. 6. The moments at which the wind gust (at $t=1000$ s) reaches each of the five turbine rows can be clearly distinguished. A sudden wind speed increase results in a power increase towards rated power in approximately $150 \mathrm{~s}$. The farm rated power is not fully achieved because of the farm losses, causing a reduction of wind speed for the turbines behind the first row. The rated power is achieved when the wind speed increases further to $25 \mathrm{~m} / \mathrm{s}$. The turbines then have to pitch the blades out of the wind in order to avoid excessive mechanical loads on the turbine or excessive power production. The pitching action goes rather fast, and the farm is able to maintain its output power within a narrow range around its rated power. The 
moments at which the wind speed gust reaches each of the five turbine rows is again clearly noticeable. The change in wind speed direction $(t=5000$ s $)$ also causes a short drop in power production, which is quickly restored by the yawing action of the turbines.

For the active power production, no differences were noted between the four scenarios a, b, c or d.

The produced reactive power for each of the four scenarios is shown in Fig. 7. It is zero for cases $a$ and $b$ by definition, and is permanently adapted in cases $\mathrm{c}$ and d to provide voltage control.

A wind farm that performs dynamic voltage control has to deliver more reactive power for a $10 \mathrm{~km}$-cable (case c) then for a $50 \mathrm{~km}$ cable (case d). The long capacitive cable damps voltage oscillations and supplies part of the required reactive power.

The resulting voltage in Slijkens and at the offshore $150 \mathrm{kV}$ - substation are shown in Fig. 8 and in Fig. 9. Without voltage control, the voltage at Slijkens fluctuates with changing wind speed. In the cases with voltage control, the voltage can well be maintained at a fixed value. However, the voltage fluctuations at Slijkens for the cases a and $\mathrm{b}$ are far less than $1 \%$, and thus well within the normal voltage fluctuations that appear on a power system. A wind farm operation strategy at which the farm reactive power is controlled at a fixed value does not result in a gravely decreased grid power quality.

All scenarios were investigated considering the three values for the current control speed TICTL $(20 \mathrm{~ms}, 200$ $\mathrm{ms}, 2 \mathrm{~s})$. However, the differences for different TICTLvalues were hardly visible. The active power oscillations are very slow, due to the acceleration and deceleration of the generators in case of wind speed changes. Therefore, the advantages of a highly advanced generator control system are not relevant in this matter.

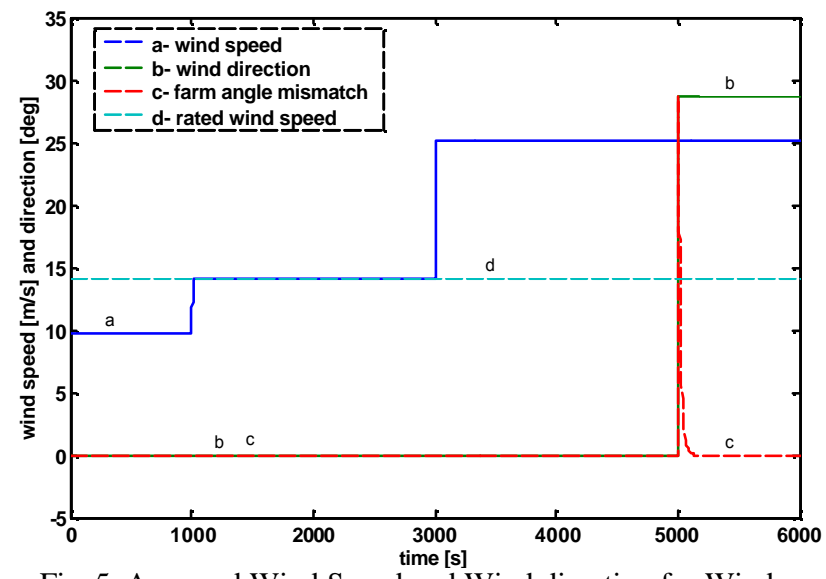

Fig. 5. Assumed Wind Speed and Wind direction for Wind Gust Simulation

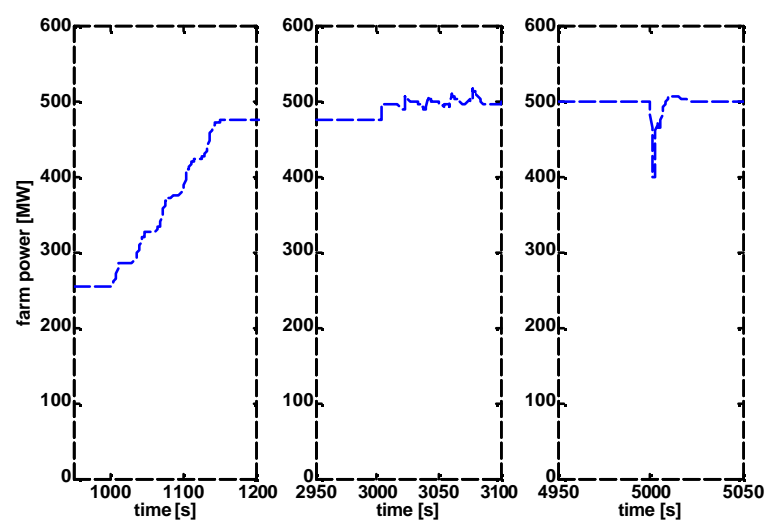

Fig. 6. Active Power Production by a 500MW-Wind Farm
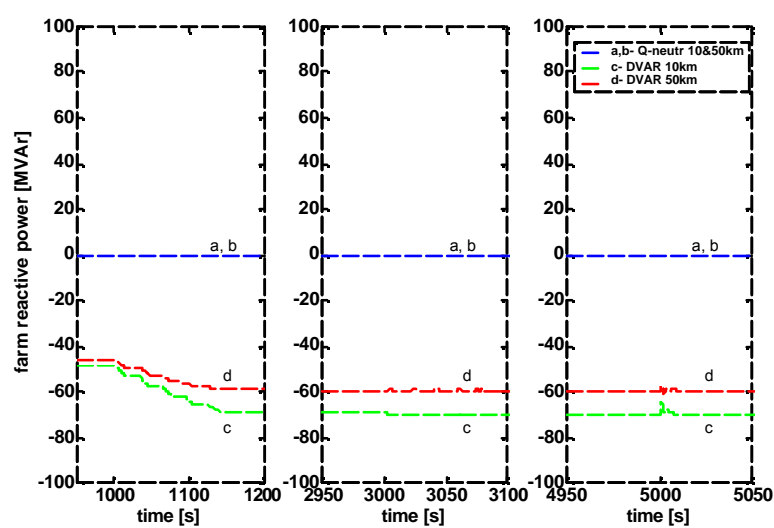

Fig. 7. Reactive Power Production by a 500MW-Wind Farm

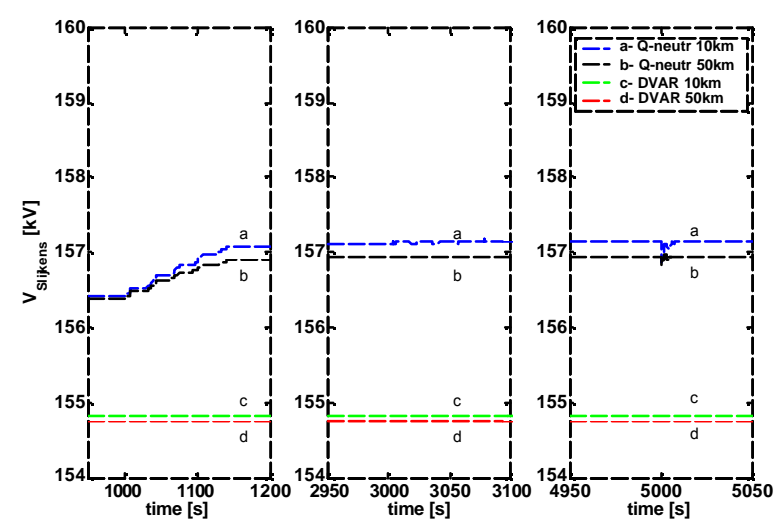

Fig. 8. Voltage at Slijkens $150 \mathrm{kV}$-substation

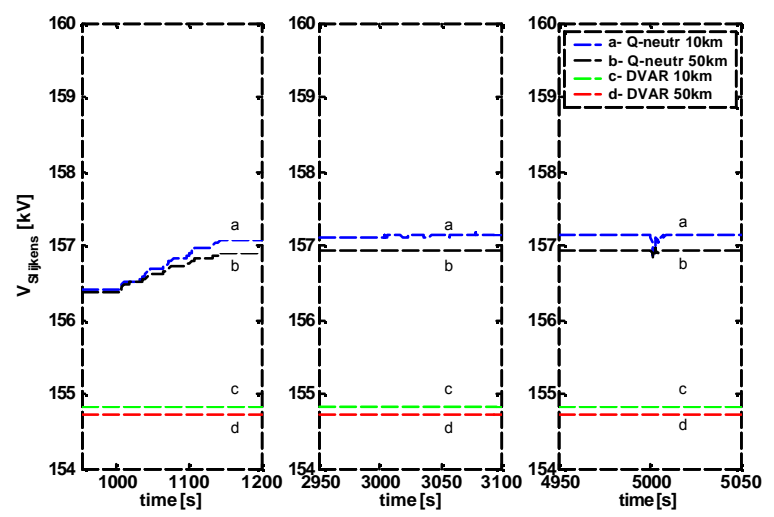

Fig. 9. Voltage at offshore $150 \mathrm{kV}$-node 
As a conclusion, during normal wind farm operation there is no incentive to set up severe grid connection requirements that demand dynamic voltage control from the wind farm. It is well sufficient to demand a controllable and fixed power factor, close to $100 \%$. However, during voltage disturbances, there will be need for dynamic voltage support, as will be discussed in the next paragraph.

\section{Voltage Disturbance due to Grid Fault}

A short-circuit at one of the two parallel lines from Slijkens to Brugge (see Fig. 4) is simulated. This causes a voltage dip at the surrounding nodes. The short-circuit lasts $0.5 \mathrm{~s}$, and it is assumed that no lines are tripped. The voltage at Slijkens during the grid fault depends on the reactive power support of the wind farm.

For the following simulation example, the wind farm is assumed to be connected as in Fig. 4, with a $150 \mathrm{kV}$ submarine cable of $10 \mathrm{~km}$. The wind speed is $13 \mathrm{~m} / \mathrm{s}$ (resulting in an active power production of $355 \mathrm{MW}$ ) and does not change during the grid disturbance.

Four scenarios for the reactive power control (Dynamic VAr control or 'DVAr') are considered:

- no DVAr, reactive power permanently controlled at zero;

- slow DVAr (TICTL = 2 s), corresponding with poorly advanced technology

- fast DVAr (TICTL = $200 \mathrm{~ms}$ ), corresponding with advanced technology

- ultra-fast DVAr $(T I C T L=20 \mathrm{~ms})$, corresponding with higly advanced technology

The current limits are set as follows:

- the maximum reference reactive current is $100 \%$ of the rated current. Reactive current control has priority on active current in case of voltage dips, as is demanded in most grid connection requirements;

- when the total current exceeds its rated value, the active power of the farm is decreased, using pitch control. The time constant for the pitch controller (as explained in [4]) is $4 \mathrm{~s}$.

The voltage at Slijkens for these four cases is shown in Fig. 10. The voltage cannot be fully restored, because the required reactive power exceeds the farm's current limits. The voltage for the fastest DVAr-control case first increases shortly after the grid fault (due to the supplied reactive current), and then decreases again after approximately 100 milliseconds. The reason for this is the decrease of active power production, in order to prevent long-lasting overcurrents. After the fault clearance, the voltage jumps to a very high value in the cases with DVAr-control, because of the high amount of reactive current delivered. The voltage is however quickly controlled towards its original value. For the cases without or with very slow DVAr-control, the voltage keeps fluctuating after the fault clearance. This is due to the influence of the various voltage controllers further in the grid (e.g. the Herdersbrug power plant).
The wind farm's active, reactive and total current for each of the four scenarios is shown in Fig. 11. The active power is shown in Fig. 12. Fast reactive power support requires also fast active power decrease, in order to limit the current.

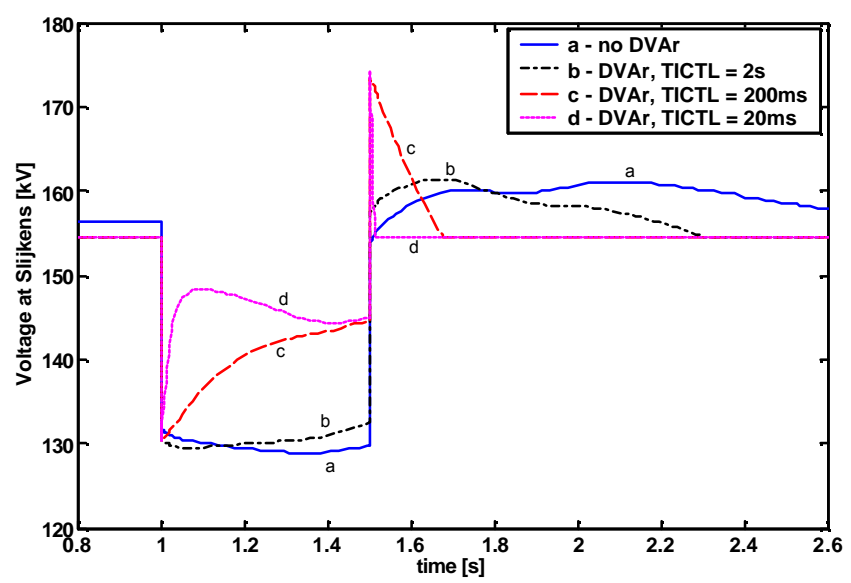

Fig. 10. Voltage at Slijkens during Grid Disturbance, for four DVAr-scenarios
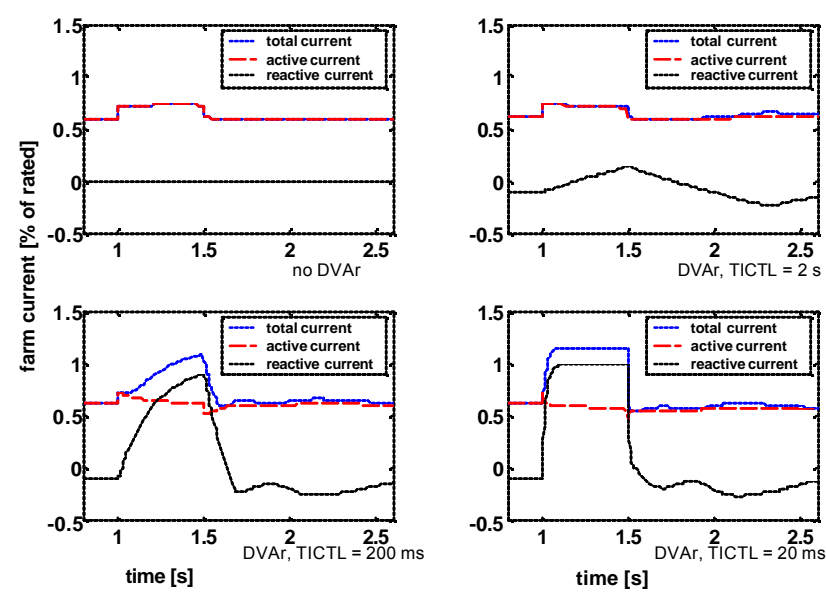

Fig. 11. Total, Active and Reactive Current of the Wind Farm during Grid Disturbance, for four DVAr-scenarios

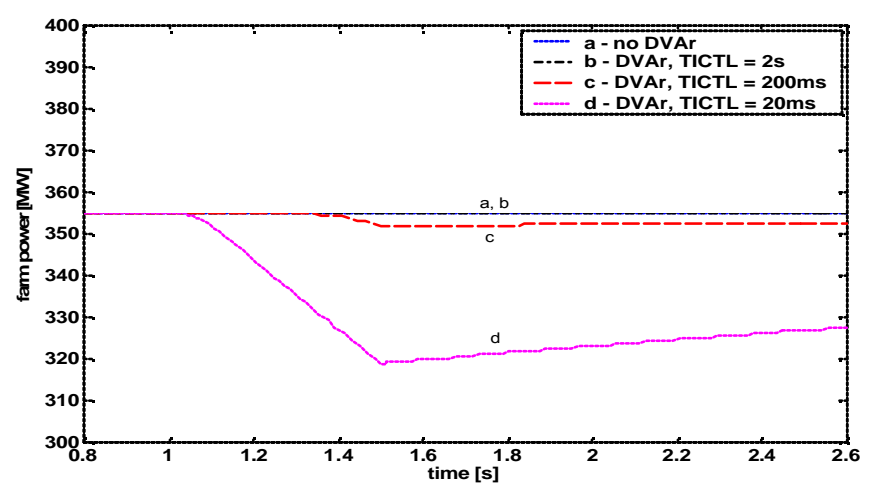

Fig. 12. Wind Farm Active Power during Grid Disturbance, for four DVAr-scenarios 


\section{Conclusions}

A generic dynamic wind farm model has been constructed, in order to assess the impact of a possible offshore wind farm on the Belgian high voltage grid. The model is used to evaluate the influence of the wind farm's dynamic VAr control on the grid voltage.

It must be noted that many parts of the model are not specific to wind turbines, but generally applicable for various kinds of generators and loads that are connected to the grid through power electronic interfaces.

For wind speed fluctuations during normal operation, the difference between dynamic VAr control and simply operating at a fixed power factor is hardly visible for a $500 \mathrm{MW}$-wind farm. It is thus a sufficient grid connection requirement towards wind farms to demand a power factor within a narrow range of $100 \%$, as long as no grid disturbances occur, and the installed power remains limited. However, depending on the amount of installed offshore wind power foreseen in the future, the grid operator may decide to set up demands for voltage control from the beginning. This way, the wind farms that will be built after the first one are treated fairly. Voltage control during normal grid operation is advised when more than approximately $1000 \mathrm{MW}$ offshore wind power is installed. This high installed power would however require major grid reinforcements to prevent line overloads [5]. In the Belgian case, the power rating of the high voltage lines puts a more severe limit to the maximum amount of installed wind power than the impact on the grid voltage.

In the case of a voltage dip due to a grid disturbance further inland, fast Dynamic VAr support by the wind farm can alleviate considerably the voltage disturbance at the point of common coupling. The alleviation of the voltage dip can save the wind farm from be tripped of the grid by its voltage protection relays. However, precautions must be made to ensure that the active power can be decreased sufficiently fast. This way, long lasting overcurrents are avoided when the full current capacity is used for reactive power support.

\section{Acknowledgement}

This research is part of the research project Optimal Offshore Wind Energy Developments in Belgium, promoted by the Belgian Federal Science Office and the IWT-GBOU project 'Embedded Generation: A Global Approach To Energy Balance And Grid Power Quality And Security'.

The authors are also grateful to the Belgian 'Fonds voor Wetenschappelijk Onderzoek (F.W.O.) - Vlaanderen' for their financial support of this work. J. Soens is a doctoral research assistant of the F.W.O.-Vlaanderen. J. Driesen holds a postdoctoral research fellowship of the F.W.O.Vlaanderen".

\section{References}

[1] S. Stoft, 'Power System Economics', John Wiley \& Sons; 1 st edition (May 17, 2002);

[2] S.M. Bolik, 'Grid Requirements Challenges for Wind Turbines', $4^{\text {th }}$ International Workshop on Large-Scale Integration of Wind Power and Transmission Networks of Offshore Wind Farms, 20-21 October, Billund, Denmark;

[3] Dussart, M.; Lauwers, P.; Magnus, S.; Laperches, Y.; 'Connection requirements for dispersed generation: evolutions of existing requirements and need for further standardization', CIRED. 16th International Conference and Exhibition on Electricity Distribution (IEE Conf. Publ No. 482), Volume: 4 , 18-21 June 2001;

[4] J. Soens, J. Driesen, R. Belmans, 'Generic Dynamic Wind Farm Model for Power System Simulations,' Nordic Wind Power Conference NWPC'04, Chalmers University of Technology, Göteborg, Sweden, 1-2 March 2004;

[5] Van Roy P., Soens J., Driesen J., Belmans R., 'Impact of off-shore wind power on the Belgian HVgrid,' European wind energy conference EWEC, June 16-19, 2003, Madrid, Spain;

[6] R. W. Delmerico, N. Miller, W. W. Price, J. J. Sanchez-Gasca, 'Dynamic Modelling of GE 1.5 and 3.6 MW Wind Turbine-Generators for Stability Simulations,' IEEE Power Engineering Society PES General Meeting, 13-17 July, Toronto, Canada; 